
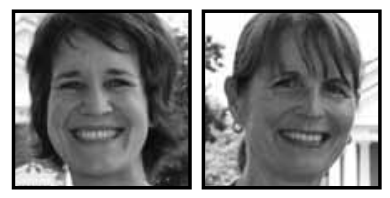

\title{
The Power of Mindset in Shaping Student Success
}

\author{
Megan Webster \& Nathalie Bossé
}

\begin{abstract}
The authors explore the assumption that intelligence is static through a case study of one student with special needs, demonstrating how a growth-oriented paradigm supports students. With a growth mindset, teachers can build the necessary confidence for students to risk learning through scaffolding the emotional, social, and cognitive components of learning.
\end{abstract}

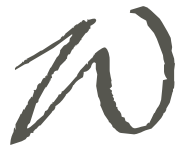

hen we first started teaching, Nathalie and I believed that while some students were gifted, others were born with less. Our job, we learned at teacher's college, was to assess the skills and preferences of our students and adjust the curriculum to meet their needs and desires. As we started working more closely with students of various personalities and "abilities," as we thought about it then, our expectations and assumptions began to erode. It didn't take long for us to see students who were "able" fail core courses, while other students-generally hard working, focused, and positive-win academic awards.

Nathalie and I have worked together at an independent school for 10 years, and have borne witness to each other's evolving ideas about student learning and the meaning of "success." Nathalie, with 35 years of teaching experience in French and Student Support, is a mentor to me, Megan, with 10 years of teaching experience in English Language Arts. Many of our expectations-and our misconceptions-about student success were brought into focus when we met an extraordinary student named Sean (all names are pseudonyms). With him we were forced to address, question, and revise our assumptions about teaching, learning, and success; as a result, we set aside our understanding of fixed and pre-determined intelligence and revised our approach to integrating students with learning exceptionalities at our school. 
When Nathalie and I read Carol Dweck's Mindset: The New Psychology of Success (2006), it helped give words to our growing intuition: People do not (necessarily) succeed because of "natural talent," but because they believe that they can succeed if they work hard. Dweck demonstrates how people who have a growth mindsetthose who believe that they can accomplish great things if they work hard and persist-are most successful in school and in life. She asks readers:

Do people with this mindset believe that anyone can be anything? No, but they believe that a person's true potential is unknown (and unknowable); that it's impossible to foresee what can be accomplished with years of passion, toil, and training. (p. 7)

Sean was one of these students: a student with a passion for stretching himself and sticking to challenging situations even-and especially-when things were not going well. Those with a fixed mindset, on the other hand, believe that their qualities are set in stone, that some people are simply "good at" a particular task, while others are not. As a result, people with a fixed mindset must always prove themselves, fearing that their "natural qualities" might be false. Those with a fixed mindset are loath to try new things in areas of lesser expertise, fearing that they might not be successful. Contrary to popular opinion, Dweck's research has shown that a growth mindset correlates more strongly with success in life than IQ, high marks in school, or "natural abilities" as expressed in a particular moment in each learner's life. Marks and IQ are perhaps better viewed as a snapshot of a student's ability at a particular moment in time, not a stable predictor of ability, as people often think. Dweck has shown that, with coaching, mindsets can change, both over a lifetime and for specific tasks.

Due to a substantial Nonverbal Learning Disability (NVLD), when Sean started kindergarten, our main goal for his education was the development of his social skills. We did not expect him to graduate from high school. His third grade psycho-educational assessment was marked by significant discrepancies between his verbal-conceptual abilities and visual-spatial abilities, suggesting he would need significant support across the curriculum. As a result of his assessment, Sean's educational program was very different from that of his peers: he was paired with a tutor for core subjects, with whom he worked on problem-solving activities in order to continue developing his abstract reasoning without becoming overwhelmed.

Sean had a very challenging profile, but he graduated from high school with honors. How did he do that? How can we cultivate successes for other students with similar learning challenges? In preparing to write this article, we wanted to hear from 
Sean, his mother, and his teachers about why Sean might have done so well. He was excited about contributing to an article, as was his mother. One cold afternoon, Nathalie and I met with Sean, his mother, student support teachers, core subject teachers, and tutors from his elementary and high school for coffee and conversation. We recorded our talk for transcription and later analysis. We opened by asking Sean, now in university, about his high school and elementary education. We asked him what he felt helped him grow, and what he thought hindered his growth. After hearing from him, we opened the conversation to the rest of the participants. After our conversation, we organized the transcripts into themes. With some tentative ideas in hand, we met again with Sean, his mother, and his psycho-educational consultant to extend our exploration of the central themes, seek elaboration, and explore counter-examples. Nathalie and I then prepared a first draft of this article that we sent to all of our participants, ensuring we were on the right track. As a result of these conversations, we feel clearer about how a growth mindset shapes one student's outcome.

Like many children with NVLD, one of the biggest challenges Sean faced was managing expected social behavior. He didn't always catch social nuances and often joined conversations with comments that seemed "out of nowhere." Sean struggled with the interpretation of facial expressions and tone from others, and he tended towards monologuing in social situations. He needed help understanding how to adopt an appropriate facial expression, tone of voice, pitch, and volume when he spoke with others. Jane, his mother, helped develop his social skills by making social norms and expectations explicit, exposing the conventions of how to keep a conversation moving forward, wait to speak, and ask for clarification. She and Sean analyzed and debriefed awkward moments so he could better manage future situations. Meanwhile, she surrounded Sean with clear messages of his strengths. At school, we reinforced the work happening at home. While being tutored, Nathalie would often hear Sean's voice rise as he became engrossed in conversations with his tutor. From her office, she would call out, "I can hear you, Seanny!" He would apologize and revert to a more appropriate volume. Over the course of the year, Nathalie had to remind him less often. At the end of a lesson in which he hadn't been reminded to check his volume, Sean would drop by Nathalie's office, inquiring, "Could you hear me today, Nathalie?"Within the year he had internalized the messages and no longer needed to be reminded or check that he was on track. Sean had both the supports to develop appropriate social behavior and the motivation to learn.

Sean could memorize almost anything and he had a highly developed vocabulary. Knowing he had learning difficulties by the time he was three, his parents decided to foster his sense of competence by capitalizing on his talents, teaching him 
the mechanics of reading and numeracy. Sean quickly gained the genuine respect of his peers in kindergarten because of his extraordinary spelling and mental arithmetic skills. He knew better and longer words than most of his peers, his teachers recall, giving him an air of sophistication. Jane believes that because he started school being acknowledged by his peers as smart, it was easier for him to later accept a curriculum that was very challenging. Research by Immordino-Yang and Damasio (2007) suggests that being perceived as competent by others is a key in allowing the brain to engage in more challenging cognitive domains.

While he could decode fluently from a very young age, Sean struggled to summarize or analyze what he read: he needed a unique approach to the development of his interpretive reading skills. It would be futile to keep asking him to summarize and interpret in the same ways that many of his peers could. For that reason, in elementary school, his tutor would read books one sentence at a time, explaining what happened, what it meant, and what she thought about when she read that sentence. Sean also noticed that when he paced or threw a basketball back and forth with a tutor, parent, or peer, that he was better able to concentrate on complex ideas. As a result, he often threw a ball back and forth with his tutor while she read aloud to him. Though Sean became more adept at summarizing, he still required support with interpretive tasks. In high school, he would have someone read complex pieces of writing with him, and prompt him to record his emergent interpretations. While those written ideas were initially simple, as he reached his senior year of high school, his work demonstrated more age-appropriate complexity and abstraction. While he may always need to read differently in order to understand complex written texts, Sean has surpassed all expectations about his capacity to understand and produce written and verbal abstract thought. While he did not learn to read and write like his peers, he can now certainly demonstrate his understanding, the ultimate goal of any reading comprehension exercise. As Benjamin Bloom (1985) famously wrote,

After forty years of intensive research on school learning in the United States as well as abroad, my major conclusion is: What any person in the world can learn, almost all persons can learn, if provided with the appropriate prior and current conditions of learning. (p. 4)

Teachers at the school worked hard to shape the standard curriculum to meet Sean's particular needs. In middle school, he had a tutor for all academic subjects and did not attend science classes. We assumed it was impossible for him to achieve in that subject while he was working so hard on developing his reading comprehension skills, literary expression, and problem solving in mathematics. At the end 
of grade 8 , Sean convinced us that he could sustain the challenge of the science curriculum so we phased it into his program. During the summer, in order to "catch him up to speed," he worked with a science teacher. By the end of the season, Sean had finished the grade 8 science curriculum. He was so successful that we blended the grades 9 and 10 curricula and he learned it all in one school year; this gave his teacher two years to prepare him for the difficult grade 10 compulsory science course. He surprised us all by getting an " $\mathrm{A}$ " on the grade 10 Ministry exam by the end of grade 9 . Sean was able to do even more than his peers could do, but he needed to do it with different learning materials and resources. The accommodation of working one on one in a low-pressure context enabled him to overtake his peers by an entire year. These extraordinary results on Ministry exams were evident when he was retested by his educational psychologist. The gap between his verbal-conceptual abilities and visual-spatial abilities had narrowed from a 55-point discrepancy in the previous testing to a mere 17-point discrepancy, surpassing even the most optimistic predictions of standardized IQ testing.

Sean says that much of his motivation to succeed in school stemmed from his desire to learn what his peers were learning. Indeed, research affirms that students are motivated to learn and succeed in school because they wish to engage in the social context of school. They want to be recognized by their peers as competent, and they want to be involved in the school community. Immordino-Yang (2008) at the Mind Brain Institute at Harvard University writes, "We want to know things because we care about them."

Sean achieved a surprising degree of social, emotional, and academic independence by the end of high school. When he was in kindergarten, we never could have imagined that he would graduate from the school on the honor roll in all academic subjects. Jane complains with a smile that he is now so popular she never sees him. He drives a car and has a job. After graduating from CEGEP on the Dean's List, Sean is now studying math in university.

What did we learn from all this? One of the most important lessons for us was rethinking our approach to problem solving, an area of particular challenge to Sean and other students with NVLD. Successful people generally solve problems by using a variety of cognitive and emotional approaches, shaping these approaches in individualistic ways to solve what appears on the surface to be the same problem for everyone. However, when students like Sean are constantly asked to solve problems using only the models provided by the instructor, they often experience nothing but frustrations (Fisher \& Rose, 2007; Ablin, 2008). Recent research in neurocognition 
suggests that teachers must distinguish between task accomplishment and task performance. Research by Catherine Snow (2008) demonstrates how students can achieve high levels of performance when they approach tasks in unique ways and have a flexible time frame. Consider, for example, learning to speak. While most babies will learn to speak by babbling, eventually producing single words and then gradually increasing the length and the complexity of their utterances, some never babble. Many babies start with longer utterances or rely for a long time on gesture before moving entirely to speech. If we put babies in school, there would be no reason to insist that all of them babble first. At the school, we often assessed students' competency acquisition on specific procedures for learning specific tasks; however, the case of Sean helped us better understand how the prescribed procedures can often be obstacles for learning. In order to develop a skill or learn a new concept, Sean, like most students, needed to work it out with varying degrees and kinds of support, and it was important for him to be evaluated on the core competency, not the execution of a particular procedure. His needs for support decreased over time as he became more adept at knowing which procedure to use for a particular problem.

Further, our experience with Sean led us to rethink traditional understandings of early intervention. Traditionally conflated with remediation, early interventions aim to build a student's capacity in a weaker area of cognitive development. The problem with this form of intervention is that it communicates to the child that he or she is not competent, and instills fears that goals may be unreachable. Immordino-Yang and Damasio (2007) have shown how fear can be a deterrent to learning. However, Sean's case demonstrates that one of the most important forms of early intervention is providing children with the opportunity to develop their excellence, so they start school with a confidence in their capacity to grow. From the beginning, Sean has believed that with time and effort he could reach some or all milestones. His parents and educators began to work on developing Sean's weaker capacities only once he felt secure.

While our assumption is that Sean, like all students, can learn and grow given the right social, emotional, and learning conditions, we do not support the axiom that anyone can do anything she sets her mind to. Just because a child believes he is athletic does not mean that he will be able to slam-dunk. Part of being a sensitive teacher is encouraging all students to grow, not necessarily to push students to achieve particular outcomes. Our goals for Sean were always growth focused: we never predicted particular outcomes because we had no idea of what the outcomes might be, but we tried to support his aspirations with an open mind. 
By witnessing the extraordinary growth of one individual, Nathalie and I now question our assumptions about the "abilities" and "natural intelligence" of our students. We better understand how necessary it is to establish a sense of competence and success through affirming early interventions. We have seen the impact of positive emotional, social, and cognitive support on a child's belief in his ability to grow. We better understand how significant the results can be when the content, process, or pace is modified in order to meet the needs of a particular student. We have observed how a focus on long-term achievement and regular monitoring of progress can also support growth. We now believe that the most important factors for student success are flexible approaches, supportive emotional and social contexts, and an unflagging belief in the ability of all students to grow.

\section{References}

Ablin, J. (2008). Learning as problem design versus problem solving: making the connection between cognitive neuroscience research and educational practice. Mind, Brain and Education, 2(2), 52-54.

Bloom, B. (1985). Developing talent in young people. United States: Ballantine Books.

Dweck, C. (2008). Mindset: The new psychology of success. United States: Ballantine.

Fisher, K., \& Rose, T. (2001). "Web of skills: how students learn." Educational Leadership, November 2001, 71-77.
Immordino-Yang, H. (2008). Emotions, social relationships, and the brain: Implications for the classroom. ASCD Express, 3(20).

Immordino-Yang, M. H., \& Damasio, A. R. (2007). We feel, therefore we learn: The relevance of affective and social neuroscience to education. Mind, Brain and Education, 1(1), 3-10.

Snow, C. (2008). Varied developmental trajectories: Lessons for educators. Mind, Brain and Education, 2(2), 59-61. 


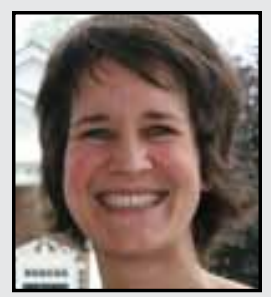

Megan Webster is a teacher and community activist, a teacher educator, and pedagogical consultant. Megan is fascinated by the learning process, and is currently conducting research for her $\mathrm{PhD}$ on high-leverage practices of professional development leaders. She's also writing curriculum that integrates volunteering, making movies based on the oral histories of survivors of genocide, working with math teachers in Kentucky, and instructing yoga.

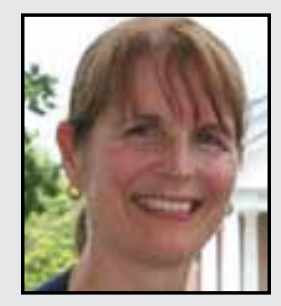

Nathalie Bossé is the Assistant Head of Curriculum and Director of the Center for Learning Enrichment at a Montreal independent school. For the past 20 years, she has developed a comprehensive student support program in her school that supports the academic success of international English Language Learner students and students with special needs. She also coordinates professional development initiatives at the school, where she has created a 10-year professional development program to teach educators how to differentiate instruction. Nathalie works with a whole-child educational approach where the teachers, support personnel, parents, and students collaboratively set goals and develop appropriate success plans. 